graphs illustrating on one hand the devastating use of nuclear energy in destroying cities and their inhabitants, and on the other the applications of nuclear energy for medical and industrial purposes (including a photograph of the first nuclear power station recently put into operation in the Soviet Union).

The last day of the session was entirely devoted to a more technical discussion of physical problems, and was held in the main lecture room of the Physical Institute. Among others, Prof. J. Rayski, of the University of Torun (who is well known to nuclear physicists in Great Britain), presented a new interpretation of the various kinds of particles recently discovered in cosmic radiation. The Academy of Sciences and the State authorities also organized official receptions of the participants, who enjoyed, during the whole duration of their stay, the most cordial hospitality.

For the occasion the Academy of Sciences, which displays considerable activity in publishing scientific periodicals and excellent journals aiming at the popularizing of science, had issued a series of valuable books. These comprise Polish translations of Madame Curie's "Traité de Radioactivité", of Mrs. Irène Joliot-Curie's shorter text-book on nuclear physics, and also of Madame Curie's delightful short biography of her husband which originally appeared in French in 1924. Another book contains a collection of articles by various Polish scientists surveying Madame Curie's work and its implications, as well as a reprint of two articles written in Polish by Madame Curie. Last, but not least, a magnificent volume has been prepared containing a reprint in the original language (mostly French or Polish) of the complete works of Madame Curie. It is interesting to see to what extent Madame Curie was anxious to write popular articles or more technical surveys on the development of radioactivity in her native language. A bronze medal bearing the figure of Madame Curie was struck to commemorate the celebration.

The present writer had the opportunity of visiting in detail the Warsaw Physical Institute and of discussing questions of common interest with Polish physicists there. He was much impressed by the activity with which the newly reorganized Institute was teeming, and with the results already achieved in a surprisingly short time in trying circumstances. The Experimental Department of the Institute, under the direction of Prof. L. Sosnowski, pursues no less than four lines of investigation. Prof. Sosnowski himself is interested in problems of semiconductors; there is a section on nuclear physics (Prof. A. Soltan), a section on the study of cosmic rays by the emulsion technique (Prof. M. Danysz), and a section on optical and X-ray spectroscopy, which was set up by the late Prof. S. Pienkowski, the creator of the Institute after the First World War. The Theoretical Physics Department oceupies a new wing which was recently built in the space of a few months and which offers a group of very keen and active young theoreticians ideal conditions of work under the leadership of the two well-known theoretical physicists, Prof. L. Infeld and Prof. W. Rubinowicz. There are flourishing centres of research in physics at the other universities, which the writer had, however, no time to visit. 'The general impression from his brief contact with Polish physicists is that of a remarkably vigorous activity and growth, worthily upholding the brilliant traditions of Polish science.

\section{SOCIAL IMPLICATIONS OF THE GENETICS OF MAN}

$\mathrm{N}$ his presidential address to the Pacific Division 1 of the American Association for the Advancement of Science, Prof. A. H. Sturtevant, of the California Institute of Technology, dealt with two matters. First, he emphasized the peculiar difficulties in the way of building up a sound body of knowledge on the formal genetics of man. 'These account for our' gross ignorance of the part played by heredity, for example, in mental differences. Secondly, he considered the problems set by the genetical consequences of atom and hydrogen bombs.

Stressing that, for their effects on heredity, there is no lower level at which high-energy radiations are harmless, Dr. Sturtevant deprecated the statement by the Chairman of the Atomic Energy Commission that "... after every test... there is a small increase in natural background radiation in some localities within the U.S.A. . . f far below the levels which could be harmful in any way to human beings ....".

Dr. Sturtevant made the point that the risk is one to which the whole of mankind is already being subjected, and, if mankind survives for many generations, the bombs already exploded will ultimately and inevitably result in an increase in the harvest of defective individuals.

Few biologists will disagree with Dr. Sturtevant's criticism of the attitude exemplified above. The genetical consequences of a world atomic war would, clearly, be trivial compared with the immediate results. If mankind cannot avoid such a war there is not much point in speculating on the genetical consequences. But if it should be avoided, then a permanent increase, no matter how small, in radioactivity, be it due to industrial waste products or to the tests mentioned by Dr. Sturtevant, might become of tremendous importance. With present knowledge we are not even in a position to make a few intelligent guesses. It is to be regretted that Dr. Sturtevant, besides deprecating the light-hearted attitude towards biological problems mentioned above, did not also consider the consequences of the development of atomic energy for peaceful purposes. It seems to the reviewer that we are taking incalculable risks by building the factories without concentrating as much energy and money on the study of the long-term biological consequences of the atomic age.

G. Pontecorvo

\section{UNITED NATIONS TECHNICAL ASSISTANCE BOARD}

\section{REPORT FOR 1953}

$T$ HE sixth report on the United Nations Expanded Programme of Technical Assistanee for Economic Development*, submitted by the Technical Assistance Board to the Technical Assistance Committee of the Economic and Social Council, describes the progress

* United Nations Technical Assistance Committee. Sixth Report of the Technical Assistance Board. Fconomic and Social CouncilEighteenth Session-Supplement No. 4 Pp. vii +267 . (New York United Nations; London: H.M.S.O., 1954.) 2.50 dollars; 17s. 6d. 10 Swiss francs. 